\title{
MEASUREMENT OF AMNIOTIC FLUID VOLUME- GRAY-SCALE VERSUS COLOUR DOPPLER ULTRASOUND
}

\author{
Mehradad Nabahati' ${ }^{1}$ Mahtab Zeinalzadeh2, Mohammad Ali Saber ${ }^{3}$, Raheleh Mehraeen ${ }^{4}$, Naser Ghaemian ${ }^{5}$, Ashraf Mahboobi ${ }^{6}$ \\ ${ }_{1}^{1}$ Assistant Professor, Department of Radiology, Shahid Beheshti Hospital, Babol University of Medical Sciences, Babol, Iran. \\ ${ }^{2}$ Associate Professor, Department of Gynaecology, Ayatollah Rouhani Hospital, Babol University of Medical Sciences, Babol, Iran. \\ ${ }^{3}$ Assistant Professor, Department of Radiology, Shahid Beheshti Hospital, Babol University of Medical Sciences, Babol, Iran. \\ ${ }^{4}$ Assistant Professor, Department of Radiology, Ayatollah Rouhani Hospital, Babol University of Medical Sciences, Babol, Iran. \\ ${ }_{5}^{5}$ Asssistant Professor, Department of Radiology, Shahid Beheshti Hospital, Babol University of Medical Sciences, Babol, Iran. \\ ${ }^{6}$ Assistant Professor, Department of Radiology, Shahid Beheshti Hospital, Babol University of Medical Sciences, Babol, Iran.
}

ABSTRACT
BACKGROUND
Amniotic fluid volume assessment is important during the pregnancy because of the association between abnormal levels of
amniotic fluid volume and perinatal morbidity and mortality. Gray-scale sonography is a method usually used to assess the
amniotic fluid volume. It is hypothesized that colour Doppler can decrease amniotic fluid volume measure. We aimed to compare
the amniotic fluid volume obtained with gray-scale and colour Doppler sonography.

\section{MATERIALS AND METHODS}

In this descriptive-analytical study, 440 pregnant women were included, who were referred to the sonography center of Shahid Beheshti Hospital in Babol, north of Iran, for foetal health assessment during 2010-2012. The exclusion criteria included the twin pregnancy and birth defects. Amniotic fluid volume was primarily measured by the gray-scale sonography using the single deepest pocket measurement method, and then the same pocket was measured by colour Doppler if the foetus did not move. Oligohydramnios was defined as an amniotic fluid volume less than $2 \mathrm{~cm}$.

\section{RESULTS}

The mean maternal age was $26.12 \pm 4.83$ years (16-42 years old). The mean gestational age of the subjects was $32.28 \pm 5.71$ weeks, ranging from 13 to 40 weeks. The mean amniotic fluid volume with gray-scale sonography was significantly more than that with colour Doppler sonography $(4.47 \pm 1.06 \mathrm{~cm}$ versus $4.26 \pm 1.32 \mathrm{~cm}, \mathrm{p}<0.0001)$. Two patients $(0.5 \%)$ with oligohydramnios were detected by gray-scale, while this rate was $28(6.4 \%)$ based on colour Doppler $(\mathrm{p}<0.0001)$.

\section{CONCLUSION}

Our results indicated that colour Doppler ultrasound can increase the diagnosis of oligohydramnios. We propose to use the colour Doppler for measurement of amniotic fluid volume in pregnant women to improve accuracy of amniotic fluid volume evaluation.

\section{KEY WORDS}

Amniotic Fluid, Doppler, Ultrasonography, Oligohydramnios.

HOW TO CITE THIS ARTICLE: Nabahati M, Zeinalzadeh M, Saber MA, et al. Measurement of amniotic fluid volume- gray-scale versus colour doppler ultrasound. J. Evolution Med. Dent. Sci. 2018;7(47):5098-5101, DOI: 10.14260/jemds/2018/1133

\section{BACKGROUND}

The measurement of amniotic fluid volume will give us important information about the function of an embryo's kidney, as well as function of placenta. Amniotic fluid volume is one of the acute characteristics of foetal movements and foetal heart rate reactivity due to direct connection to the health of the foetus and high sensitivity and predictive values.(1,2) There are two types of amniotic fluid volume measurement, including amniotic fluid index and single deepest pocket. Amniotic fluid index is one of the most important components to evaluate the biophysical profile. $(3,4)$

In most cases, the diagnosis of low amniotic fluid volume is not possible or difficult. $(5,6)$

'Financial or Other Competing Interest': None.

Submission 08-10-2018, Peer Review 01-11-2018,

Acceptance 09-11-2018, Published 19-11-2018.

Corresponding Author:

Dr. Mehradad Nabahati,

Assistant Professor,

Department of Radiology, Shahid Beheshti Hospital,

Babol University of Medical Sciences,

Ganjafrooz Street, Babol, Mazandaran Iran.

E-mail:mehrdadnabahati@gmail.com

DOI: $10.14260 /$ jemds/2018/1133

\section{(c) $(1) \ominus$}

Sonography is a non-invasive and reproducible method and its inter-observer and intra-observer errors are less than 0.7. $(7,8)$ In the sonography centers, measurement of amniotic fluid index and single deepest pocket is often conducted by gray-scale sonography. Considering that in the third trimester of pregnancy, the umbilical cord is very clear or hypoechoic, it is observed as amniotic fluid. If the umbilical cord is found in the measured pocket, it might not be seen on gray-scale sonography, but is diagnosed by colour Doppler ultrasonography, consequently, it is effective on the amniotic fluid measurement. $(9,10)$

Practically, in several cases, there are conflicting results between colour Doppler sonography and gray-scale sonography in measurement of amniotic fluid volume, that is, colour Doppler reports a lower or normal range for amniotic fluid volume, but the gray-scale sonography shows significantly higher ranges for the same amniotic fluid volume. Considering these differences, we aimed to assess the accuracy of the gray-scale sonography in comparison with colour Doppler sonography in measurement of amniotic fluid volume, supposing that colour Doppler imaging may be associated with increased diagnostic accuracy of low amniotic fluid volume. 


\section{MATERIALS AND METHODS}

In this descriptive-analytical study, 440 second or third trimester pregnant women were enrolled, who were routinely referred to the sonography center of Shahid Beheshti Hospital in Babol, Northern Iran, for foetal health assessment during 2010-2012. The inclusion criteria for this study included gestational age of 20-40 weeks by the certain last menstrual period and uncomplicated singleton pregnancy. All cases of twin pregnancy and birth defects were excluded from the study.

In this method, the amniotic fluid volume was firstly measured by the gray-scale sonography using the single deepest pocket measurement method, and then the same pocket was measured by colour Doppler if the foetus did not move. If the foetus moved during the measurement which caused the displacement of the umbilical cord or organs, the procedure should be repeated, and the other quadrants were used for measurement. All sonographies and record information were performed by a doctor and two types of 9900 Medison ultrasound equipped with the colour Doppler with 3 to $7 \mathrm{MHz}$ probes and the Acuson X-300 with 2 to 5 MHz probes.

Variables such as foetal age, maternal age and obesity, parity and amniotic fluid volume measured by gray-scale and Doppler sonography were recorded for each mother (maternal obesity was divided into thin, normal, and obese which the criteria were based on the resolution of sonographic images affected by the patients' subcutaneous fat). According to the latest classification, the amniotic fluid volume was categorized as follows: less than $2 \mathrm{~cm}$, oligohydramnios; 2 to $8 \mathrm{~cm}$, normal; more than $8 \mathrm{~cm}$, polyhydramnios. ${ }^{(11)}$

The obtained data were analysed by SPSS software. We used descriptive analysis to present characteristics of the subjects. Chi-square and paired t-test were used to compare the results between gray-scale and colour Doppler methods. $\mathrm{P}<0.05$ was considered significant. We considered gray-scale sonography as the standard method to measure the amniotic fluid volume, and compared the findings by colour Doppler imaging with the gray-scale results.

The present study was approved by the research ethical committee of Babol University of Medical Sciences (Code: MUBABOL.REC.1390.7). The written informed consent was taken from all pregnant women. The subjects' information were kept confidential.

\section{RESULTS}

Overall, 440 subjects were included in this study. The mean maternal age was $26.12 \pm 4.83$ years old, ranging from 16 to 42 years old. The mean gestational age of the study population was $32.28 \pm 5.71$ weeks (13-40 weeks). There were 278 (63.2\%) nulliparous and 162 (36.8\%) multiparous. Regarding maternal obesity, $208(47.3 \%)$ were thin, 172 (39.1\%) were normal and $60(13.6 \%)$ were obese).

The mean amniotic fluid volume was $4.47 \pm 1.06 \mathrm{~cm}$ with gray-scale sonography versus $4.26 \pm 1.32 \mathrm{~cm}$ with colour Doppler sonography, which the difference was significant $(p<0.0001)$. In Figure 1, for each designated amniotic fluid volume $(<2 \mathrm{~cm}, 2-8 \mathrm{~cm},>8 \mathrm{~cm})$, on average the colour Doppler amniotic fluid volume was less than that of the gray scale.
Table 1 shows the results of amniotic fluid volume measurement by gray-scale and colour Doppler sonographies in frequency. Two patients $(0.5 \%)$ with oligohydramnios were detected by gray-scale, while this rate was $28(6.4 \%)$ based on colour Doppler, which the difference was significant according to chi-square test $(\mathrm{p}<0.0001)$. Gray-scale and colour Doppler measures were strongly and positively correlated $(r=+0.898, p<0.0001)$.

\begin{tabular}{|c|c|c|c|c|}
\hline \multirow[b]{2}{*}{ 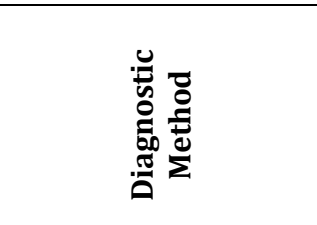 } & \multicolumn{3}{|c|}{ Diagnostic Findings } & \multirow[b]{2}{*}{$\frac{\stackrel{0}{\Xi}}{3}$} \\
\hline & 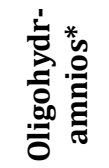 & 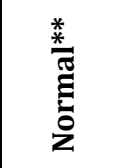 & 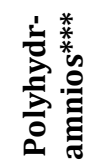 & \\
\hline $\begin{array}{c}\text { Colour Doppler } \\
\text { sonography }\end{array}$ & $\begin{array}{c}28 \\
(6.4 \%)\end{array}$ & $\begin{array}{c}411 \\
(93.4 \%)\end{array}$ & $\begin{array}{c}1 \\
(0.2 \%)\end{array}$ & \multirow{2}{*}{$<0.0001$} \\
\hline Gray-scale sonography & $\begin{array}{c}2 \\
(0.5 \%)\end{array}$ & $\begin{array}{c}437 \\
(99.3 \%)\end{array}$ & $\begin{array}{c}1 \\
(0.2 \%)\end{array}$ & \\
\hline $\begin{array}{r}\text { Table 1. } \\
\text { and nor } \\
\text { co }\end{array}$ & 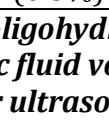 & 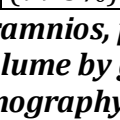 & $(10-7)$ & nnios \\
\hline
\end{tabular}

* Amniotic fluid volume less than $2 \mathrm{~cm}$.

** Amniotic fluid volume between 2 and $8 \mathrm{~cm}$.

*** Amniotic fluid volume more than $8 \mathrm{~cm}$.
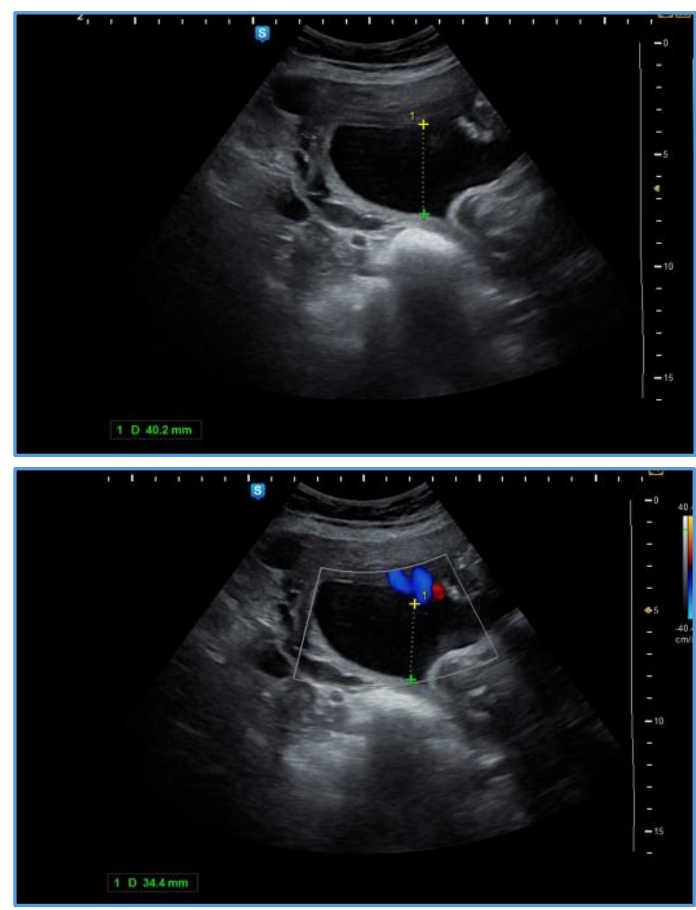

Figure 1. Amniotic fluid volume measurement with the use of gray-scale and colour Doppler sonography

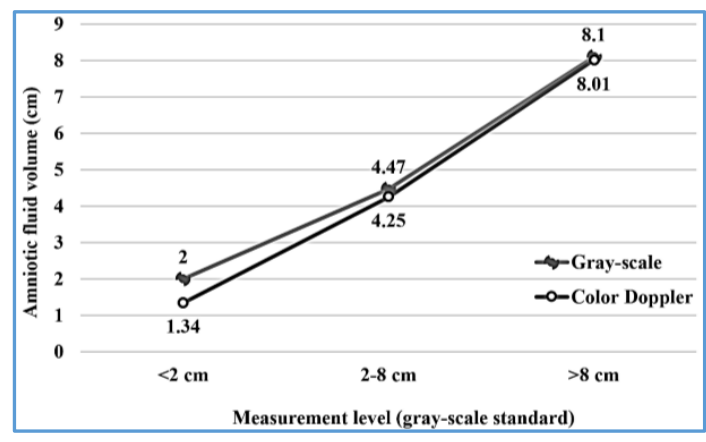

Figure 2. Comparison of mean gray-scale and colour Doppler readings of amniotic fluid volume by measurement level 


\section{DISCUSSION}

In this study, we compared the results of amniotic fluid volume measurement between gray-scale and colour Doppler. As mentioned, the number of oligohydramnios patients diagnosed by colour Doppler was significantly higher than that diagnosed by gray-scale. A number of studies were performed to compare the gray-scale and colour Doppler sonographies on amniotic fluid volume. Most of the studies were related to the increasing effect of colour Doppler on diagnosis of the oligohydramnios.

In a study by Magann et al.(12) investigating the clinical relationship between amniotic fluid volume and sonography, only single deepest pocket was preferred to assess the amniotic fluid volume rather than amniotic fluid index due to increase in the diagnosis of oligohydramnios. Another study by Magann et al.(13) showed that the mean amniotic fluid index, single deepest pocket, and two-diameter pocket values were significantly lower among subjects at $<37$ weeks' gestation compared with those at $\geq 37$ weeks' gestation. The authors concluded that the single deepest pocket might be preferable method to assess amniotic fluid volume due to less false-positive diagnosis of either oligohydramnios or polyhydramnios. Another research indicated that amniotic fluid index and also single deepest pocket technique were both significantly associated with increased detection of low amniotic fluid volume, when they were used simultaneously with colour Doppler. In fact, amniotic fluid volume measurement was associated with a reduction of $20 \%$ and $18 \%$ when using colour Doppler with amniotic fluid index and single deepest pocket, respectively.(14) Bianco et al.(15) compared the measurement of amniotic fluid index with and without colour Doppler. Oligohydramnios were investigated using both methods. amniotic fluid index was significantly reduced and thus diagnosis of oligohydramnios increased in cases that colour Doppler was added to the standard procedure. These results are consistent with our findings.

On the other hand, Zlatnik et al.(16) who examined the effect of colour Doppler on the amniotic fluid index measurements, stated that amniotic fluid index measured by Doppler increases false-positive diagnosis of oligohydramnios and also may underestimate polyhydramnios. In a recent study by Odibo et al.(17) they declared that use of colour Doppler sonography causes overdiagnosis of low amniotic fluid volume.

We witnessed a good correlation between gray-scale and colour Doppler in our study, allowing one to predict the amniotic fluid volume with colour Doppler from the grayscale value. However, it was observed that the agreement of gray-scale and colour Doppler was mainly on normal or high amniotic fluid volume measures and not on oligohydramnios.

Measurement of amniotic fluid volume during pregnancy is very important. This is because of that oligohydramnios can increase risk of perinatal/neonatal mortality and morbidity.(18-20) Therefore, the accuracy of the techniques should be considered in this regard by the clinicians. Grayscale sonography as a standard method has a widespread usage in measurement of amniotic fluid volume, however, we believe that addition of colour Doppler will improve accuracy of amniotic fluid volume evaluation.

\section{CONCLUSION}

The results of the present study showed that colour Doppler sonography can enhance the diagnosis of oligohydramnios.
Considering that oligohydramnios can be associated with perinatal morbidity and mortality, addition of colour Doppler may be especially useful in cases where standard amniotic fluid volume measurement is in the low-normal range.

\section{ACKNOWLEDGEMENT}

The authors are thankful to the Vice Chancellor for Research of Babol University of Medical Sciences for supporting our project.

\section{REFERENCES}

[1] Wood SL, Newton JM, Wang L, et al. Borderline amniotic fluid index and its relation to foetal intolerance of labor: a 2-center retrospective cohort study. J Ultrasound Med 2014;33(4):705-11.

[2] Morris R, Meller CH, Tamblyn J, et al. Association and prediction of amniotic fluid measurements for adverse pregnancy outcome: systematic review and meta-analysis. BJOG 2014;121(6):686-99.

[3] Kehl S, Schelkle A, Thomas A, et al. Single deepest vertical pocket or amniotic fluid index as evaluation test for predicting adverse pregnancy outcome (SAFE trial): a multicenter, open-label, randomized controlled trial. Ultrasound Obstet Gynecol 2016;47(6):674-9.

[4] Rosati P, Guariglia L, Cavaliere AF, et al. A comparison between amniotic fluid index and the single deepest vertical pocket technique in predicting adverse outcome in prolonged pregnancy. J Prenat Med 2015;9(1-2):12-5.

[5] Dubil EA, Magann EF. Amniotic fluid as a vital sign for foetal wellbeing. Australas J Ultrasound Med 2013;16(2):62-70.

[6] Fitzpatrick K, Tuffnell D, Kurinczuk J, et al. Incidence, risk factors, management and outcomes of amniotic-fluid embolism: a population-based cohort and nested case-control study. BJOG 2016;123(1):100-9.

[7] Pourissa M, Refahi S, Pezeshky R, et al. Radial amniotic fluid index as a new and accurate method for measurement of amniotic fluid volume. Acta Medica Iranica 2006;44(2):101-4.

[8] Sarris I, Ioannou C, Chamberlain P, et al. Intra-and interobserver variability in foetal ultrasound measurements. Ultrasound Obstet Gynecol 2012;39(3):266-73.

[9] Fok W, Chan LY, Lau TK. The influence of foetal position on amniotic fluid index and single deepest pocket. Ultrasound Obstet Gynecol 2006;28(2):162-5.

[10] Magann EF, Ounpraseuth S, Chauhan SP, et al. Correlation of ultrasound estimated with dyedetermined or directly measured amniotic fluid volume revisited. Gynecol Obstet Invest 2015;79(1):46-9.

[11] Rumack CM, Wilson SR, Charboneau JW, et al. Diagnostic ultrasound. Vol. 2. 4th edn. Philadelphia: Elsevier 2011: p. 1357. 
[12] Magann EF, Sandlin AT, Ounpraseuth ST. Amniotic fluid and the clinical relevance of the sonographically estimated amniotic fluid volume: oligohydramnios. J Ultrasound Med 2011;30(11):1573-85.

[13] Magann EF, Sanderson M, Martin JN, et al. The amniotic fluid index, single deepest pocket, and twodiameter pocket in normal human pregnancy. Am J Obstet Gynecol 2000;182(6):1581-8.

[14] Magann EF, Chauhan SP, Barrilleaux PS, et al. Ultrasound estimate of amniotic fluid volume: colour Doppler over-diagnosis of oligohydramnios. Obstet Gynecol 2001;98(1):71-4.

[15] Bianco A, Rosen T, Kuczynski E, et al. Measurement of the amniotic fluid index with and without colour Doppler. J Perinat Med 1999;27(4):245-9.

[16] Zlatnik MG, Olson G, Bukowski R, et al. Amniotic fluid index measured with the aid of colour flow Doppler. J Matern Foetal Neonatal Med 2003;13(4):242-5.
[17] Odibo IN, Whittemore BS, Hughes DS, et al. Addition of colour Doppler sonography for detection of amniotic fluid disturbances and its implications on perinatal outcomes. J Ultrasound Med 2017;36(9):1875-81.

[18] Ashok KH, Umadevi N. Maternal and perinatal outcome in oligohydramnios in term low risk pregnancy. J Evolution Med Dent Sci 2017;6(12):9369.

[19] Gumus II, Koktener A, Turhan NO. Perinatal outcomes of pregnancies with borderline amniotic fluid index. Arch Gynecol Obstet 2007;276(1):17-9.

[20] Singh A, Ramadevi Y. Maternal and foetal outcomes in pregnancy with isolated oligohydramnios in third trimester. J Evolution Med Dent Sci 2016;5(78):57757. 